\title{
E. Ann Ellis Roundtable Discussion of Energy Dispersive Spectroscopy Revisited
}

\section{Eduardo Rosa-Molinar ${ }^{1}$}

${ }^{1 .}$ Microscopy and Analytical Imaging Research Resource Core Laboratory, Department of Pharmacology and Toxicology and Neuroscience Graduate Program, The University of Kansas, Lawrence, USA.

I met Elizabeth Ann Ellis in 1981 in Atlanta, Georgia at the Thirty-ninth Annual Meeting of the Electron Microscopy Society of America. At that time, Ann was well known for her extensive knowledge of electron microscopy (EM), especially specimen preparation, chemistry, and formulation of embedding resins. Despite her established reputation, she never stopped her quest to improve microscopy. She never stopped sharing the knowledge and skills gained from her quest. She never stopped urging her colleagues to address problems by thinking methodically and critically. In her abstract for the 2013 Microscopy Society of America meeting, Technologists' Forum: Roundtable Discussion of Energy Dispersive Spectroscopy (EDS), she posed 22 questions critical to the quest for ways to overcome the challenge of using EDS for biological materials [1-2]. In doing so, she reminded microscopists that $90 \%$ of their work is specimen preparation and pointed out the dilemma posed by the need to prevent both loss of elements and charging in preparing specimen for EDS [4-8].

In EM, the most common source of artefact is charging of non-conductive biological samples [4-8]. Charging results in image distortions, poor image quality, image drift, and image contrast issues [4-8]. Charging is the result of the build-up of incident electrons along the non-conductive sample surface and their uncontrolled escape [4-8]. An ultra-thin coating $(2-20 \mathrm{~nm})$ of electrically-conducting metal - such as gold $(\mathrm{Au})$, gold/palladium $(\mathrm{Au} / \mathrm{Pd})$, platinum $(\mathrm{Pt})$, silver $(\mathrm{Ag})$, chromium $(\mathrm{Cr})$ or iridium $(\mathrm{Ir})-$ on the non-conductive biological sample surface is commonly used to prevent such charging [9]. However, the ultra-thin coating of an electrically-conducting metal prevents further quantitative and qualitative chemical mapping and analyses such as that in energy dispersive spectroscopy (EDS) [9].

Here we describe results of our efforts to develop an en-bloc conductive stain using non-destructive high-resolution imaging by scanning transmission electron microscopy (STEM; see Figure 1) that enables chemical mapping by EDS and electron energy loss spectroscopy (EELS; see Figure 2). We believe that this en-bloc conductive stain provides an unprecedented opportunity to image and explore metal ions in the nanoscale cellular compartments of synapses.

Ann's [1,9] quest continues with those whose work and lives she influenced [10].

References:

[1] Ellis, E. A., Technologists' Forum: Roundtable Discussion of Energy Dispersive Spectroscopy. Microsc. Microanal. 19, S2 (2013), p. 2022.

[2] Echlin, P., Handbook of Sample Preparation for Scanning Electron Microscopy and X- Ray Microanalysis, (Springer, New York).

[3] Egerton, R. F., Crozier, P. A. and Rice, P., Ultramicroscopy 23 (1987), p. 305.

[4] Cazaux, J., Scanning 26 (2004), p. 181.

[5] Joy, D. C., Scanning 11 (1989), p. 1. 
[6] Pawley, J. B., Scanning Electron Microscopy 1 (1972), p. 153.

[7] Robinson, V. N. E., Journal of Physics E: Scientific Instruments 8 (1975), p. 638.

[8] Shaffner, T. J. and Van Veld, R. D., Journal of Physics E: Scientific Instruments 4 (1971), p. 633.

[9] Pendleton M. W et al, Microsc. Microanal. 14, S2 (2008), p. 704.

[10] Research partially supported by grants to ER-M from NIH (MH-106245) and NSF (HRD$1137725)$.

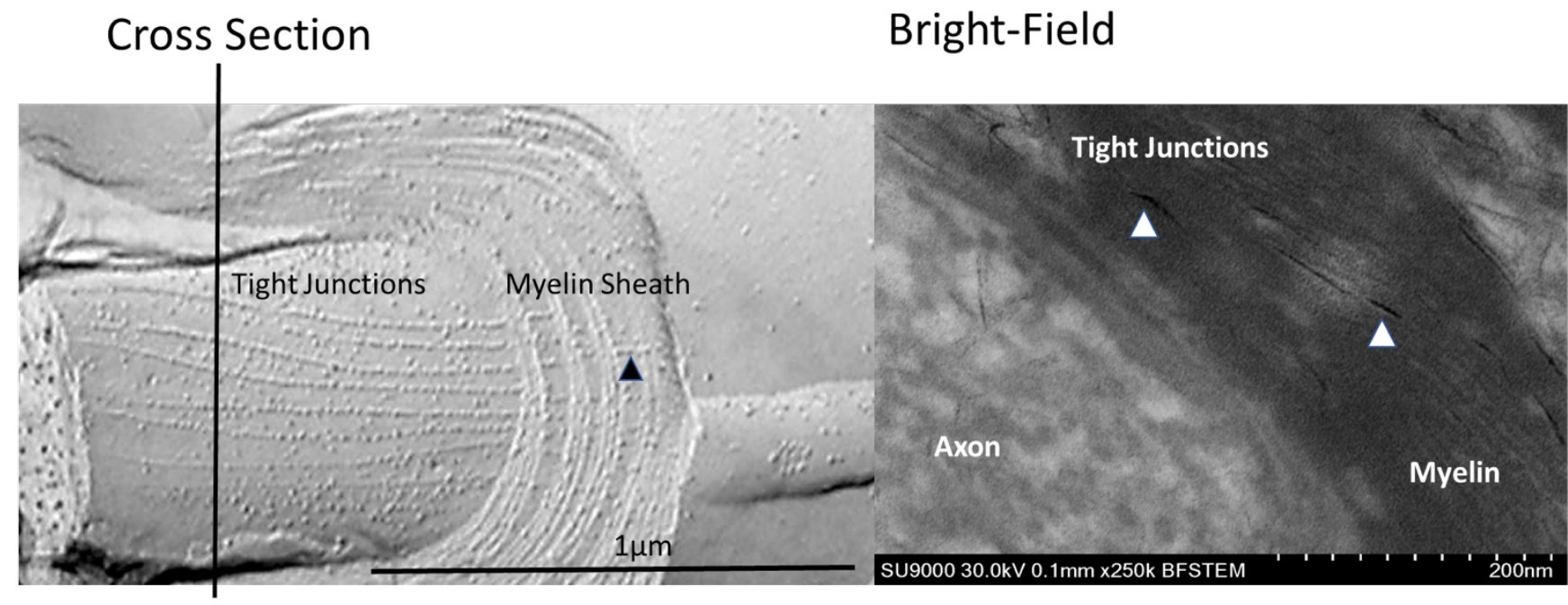

Figure 1. Freeze-fracture replica showing longitudinal rows of interlamellar tight junctions (black arrowheads) along the axon surface and extending within the spiral intramyelinic compartment through the myelin sheath. Note that interlamellar tight junctions are unique to central nervous system myelin. Bright-field STEM image of a $50 \mathrm{~nm}$ cross section through a myelinated axon (left image) exposed to lanthanum. Lanthanum is present in tight junctions (white arrowheads) located within the outer myelin lamellae of thick myelin sheaths.

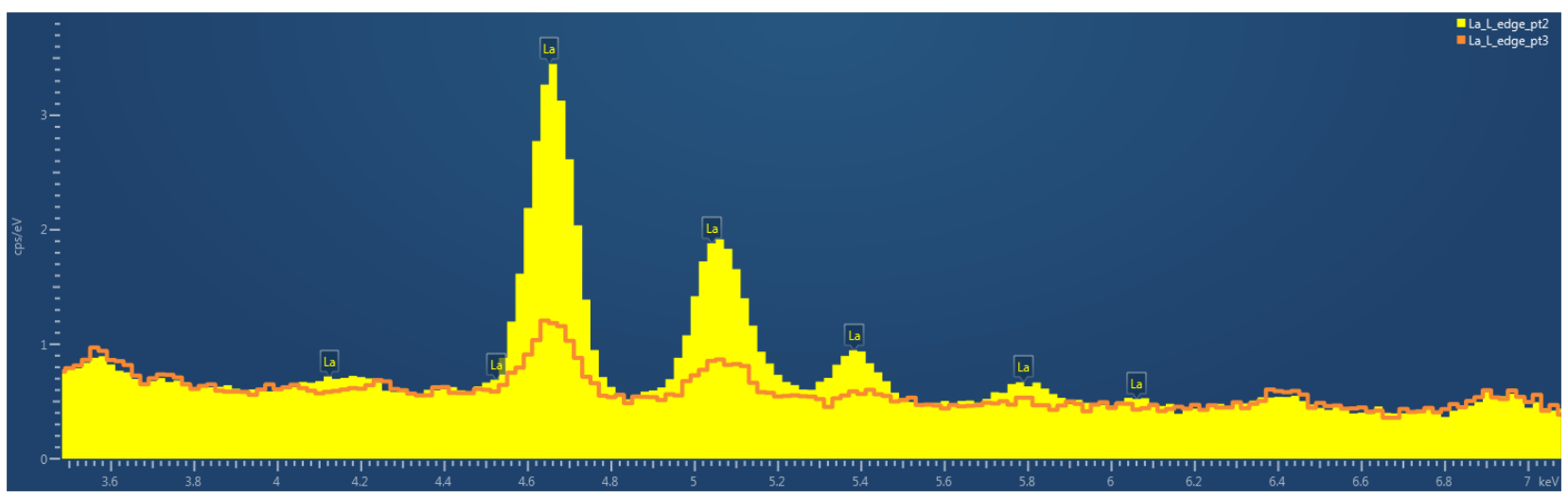

Figure 2. La L-series x-ray peaks (in yellow) acquired simultaneously with EELS (orange line) show that lanthanum is present in tight junctions located within the outer myelin lamellae of thick myelin sheaths. 